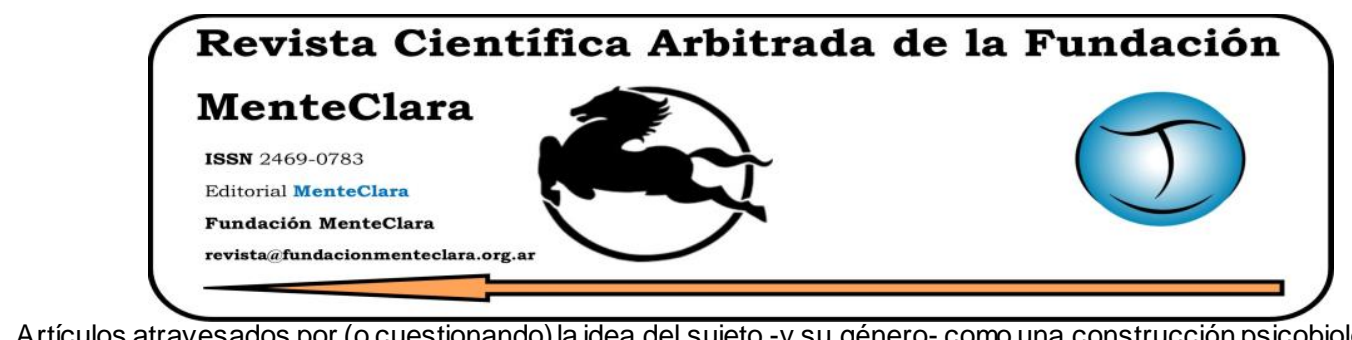

Artículos atravesados por (o cuestionando) la idea del sujeto -y su género- como una construcción psicobiológica de la cultura. Articles driven by (or questioning) the idea of the subject -and their gender- as a cultural psychobiological construction

Vol. 5 (2020), enero-diciembre

ISSN 2469-0783

https: / / datahub.io/ dataset/2020-5-e165

\title{
THE PHENOMENOLOGICAL METHOD: IN THE LIGHT OF OUR MIND KNOWING PHENOMENOLOGICAL FORMS AND OUR AW ARENESS KNOWING PHENOMENOLOGICAL BEING
}

\author{
EL MÉTODO FENOMENOLÓGICO: A LA LUZ DE NUESTRA MENTE QUE TOMA \\ CONOCIMIENTO DE LAS FORMAS FENOMENOLÓGICAS Y LA CONCIENCIA QUE \\ TOMA CONOCIMIENTO DEL SER FENOMENOLÓGICO
}

Rudolph Bauer rbauer@rsbauer.net

Center for Consciousness Studies and Washington Center for Phenomenological and Existential Psychotherapy Studies. United States of America

Cómo citar este artículo / Citation: Bauer R. (2020). "The Phenomenological Method: In the Light of Our Mind Knowing Phenomenological Forms and Our Awareness Knowing Phenomenological Being". Revista Cientifica Arbitrada de la Fundación MenteClara, Vol. 5 (165). DOI: https://doi.org/10.32351/rca.v5. 165

Copyright: (C) 2020 RCAFMC. Este artículo de acceso abierto es distribuido bajo los términos de la licencia Creative Commons Attribution 4.0 International License (CC BY 4.0). Recibido: 15/08/2020. Aceptado: 19/08/2020 Publicación online: 21/08/2020

Conflicto de intereses: None to declare.

\begin{abstract}
This article reviews the unfolding of the transcendental phenomenological reduction process and reviews the unfolding of the ontological phenomenological reduction process as articulated by Heidegger and contemporary ontological phenomenology. It also reviews the phenomenological reduction in the light of contemporary Existential Phenomenology. Our discussion is elaborated in light of the two ways of knowing: the knowing of mind knowing phenomena and the knowing of awareness knowing Being integrating it with the Eastern philosophical tradition of Tibetan Dzogchen and vajrayāna-tantric-Buddhism. The focus has been on the power of the intertwining of these ontic-ontological capacities.
\end{abstract}




\section{Resumen}

Este artículo revisa el desarrollo del proceso de reducción fenomenológica trascendental y revisa el desarrollo del proceso de reducción fenomenológico ontológico tal como lo articula Heidegger y la fenomenología ontológica contemporánea. También analiza la reducción fenomenológica a la luz de la fenomenología existencial contemporánea. Nuestra discusión se elabora a la luz de las dos formas de conocer: el conocimiento de la mente que conoce fenómenos y el conocimiento de la conciencia que conoce al Ser integrándolo con la tradición filosófica oriental del Dzogchen tibetano y del budismo vajrayāna-tántrico-. Se hizo foco en el poder del entrelazamiento de estas capacidades óntico-ontológicas.

Keyw ords: tantra; field of Being; awareness; phenomenology; da sein

Palabras Claves: tantra; campo del ser; consciencia; fenomenologia; da sein 


\section{Introduction}

The important phenomenological distinction between the mind and awareness was not always present in continental phenomenology. The earlier forms of phenomenology formulated by Husserl were about the mind intuitively knowing the essence of phenomena. With the unfolding of Heideggerian ontological phenomenology as well as the ontological phenomenology of Merleau Ponty, this distinction between our two ways of knowing became more apparent in continental phenomenology. This foundational phenomenological distinction between the mind knowing phenomena and awareness knowing Being brought forth the integrated phenomenological understanding of human beings as ontic ontological beings.

\section{Two Ways of Knowing In Contemporary Continental}

\section{Phenomenology}

Within Contemporary Phenomenology there is understanding that human beings have two ways of knowing. Our mind knows phenomena and our awareness knows Being. Our mind knows forms. Our mind knows things both subtle and gross, faces, hands, buildings, trees, math formulas! Our mind knows subject and our mind knows otherness. Our mind knows duality. Our mind knows me and you, us and them, and this and that. The mind knows beings and entities, infinite numbers of beings and entities.

Our mind knows time, and our mind knows about time as the past and our mind knows the time of present moment and our mind has a the sense of future time perspective. The mind knows things and knows beings. Our mind knows difference. Our mind knows conceptually, feels affectively, imagines through imagery, the mind has sensation and the 
mind has memory. The mind knows dualistically. Our mind knows difference.

\section{The Non Conceptual Knowing of Awareness Knowing Being}

Our Awareness knows Being directly and Non Conceptually. Our awareness knows the Beingness of beings directly and experientially. Awareness knows prereflectively and non dualistically. In eastern philosophical tradition of Tibetan Dzogchen this direct non conceptual and prereflective knowing of Being was called gnosis or jnana.

Being is not a being and yet Being self manifest as all beings. Being manifest Being within beings, as their own Being. Being itself is not an entity and not a being. Being is non dualistic. Being is oneness. Awareness knows non dualistically and experiences the non duality of the world. Being as Being is oneness and the pervasiveness of oneness. Being is pure openness, and Being is pure spaceousness.

Being self manifest as radiant light and Being is creative resonance. Being is self manifestation and Being is manifesting. Being self manifest as the Being of beings. Awareness knows Being and our awareness is the knowingness of our own Being. To use Heideggerian language Being is Phusis. And Being is Aletheia. Being is the unconcealment of Beingness.

Being is multidimensional. Primordial Being manifest dualities, although Being is completely non dualistic. By Becoming aware of our own awareness, we can experience primordial awareness which is the ground of Being and the ground of all beings. Primordial awareness is Pure Being. Awareness is the knowingness of Being. Awareness is Being knowing Being. Being knows Being and the Beingness of all the beings. Awareness is timeless and within being within our awareness we can 
experience timeless and time simultaneously. We can experience timelessness in time simultaneously.

Being liberates us, this simultaneous experience is a path of self liberation. The experience of timeless awareness and time simultaneously reflects the union of the knowingness of our mind in union with the knowingness of our awareness. This union brings forth living and being in a field of Being infinite in its horizons, vast and multidimensional.

\section{The Early Phenomenology of Husserl: The Intuitive Knowing of our Mind Knowing the Essence of Phenomena}

In the early phenomenology of Husserl, Husserl studied phenomenologically the intuitive knowing of our mind and the intuitive experiencing of lived experience through our Mind. In this context intuition means the direct knowing of the nature of phenomena. Husserl's early phenomenological study of the mind and the study of the constitution -manifestation- of mind was by and through forms of Transcendental Knowing. For Husserl Transcendental Knowing reflected the multidimensional quality of intuitive knowing and the translucidity of intuitive knowing. Transcendental knowing is the medium of the trans -lucidity of direct knowingness (Husserl, 1964).

Transcendental phenomenology can have multidimensional views of the same phenomena, as well as varied views of the same lived experience of the same phenomena. There are different stages and dimensions of Transcendental knowing. In Husserl's Transcendental phenomenology, phenomena is multidimensional and transcendental knowing is also multidimensional. The natural dimensions of our experiential life is described by Husserl as the Ordinary Life World. 
In Husserl's later phenomenology, there was the elemental dimension of Being that actually manifest the ordinary life world. And in Heideggerian phenomenology there is the ground of Being which is the source of beings and the source of the elemental dimension as well as the ordinary life world dimension. This ground of Being is also primordial awareness self -manifesting as everything and anything.

\section{Direct Knowing and Direct Perception of the Essence of Phenomena}

The primary experience of Husserl's Transcendental phenomenology of the mind is that the Transcendental mind can intuitively and directly perceives the essence of phenomena. The essence of phenomena is the essential what-ness of phenomena. Transcendental knowing is our transcendental gazing into the appearance of phenomena and gazing into the manifestation of phenomena. Transcendental knowing focuses on the essence of the subtle experience of both the essence of phenomenological form and the essence of formless pure consciousness. We consider that the word essence reflects the what-ness or the nature of our experience of the phenomena.

\section{The Essence of the Phenomenological Method}

The capacity to gaze into the appearance of phenomena and to gaze into the manifestation of phenomena and apprehend the essence of the phenomena is the essence of most forms of phenomenology. This direct perception of the essence of phenomena is also of the essence of what Husserl called the process of phenomenological reduction. The wording and the understanding of the phenomenological reduction was always a 
never ending unfolding process of Husserl's investigation of our mind's intuitive knowing of what is.

Phenomenology is primarily a perceptual experience of direct knowing or immediate intuitive experiential knowing. The phenomenology of Husserl focused on the direct knowing or our direct perception of the essence of phenomena, the what-ness of phenomena. Husserl called this direct knowing Intuition.

In the later phenomenological presentation of Martin Heidegger, the essence of phenomenology was our direct knowing of the Beingness of the phenomena. Phenomenology becomes an ontology, a phenomenological ontology. The Being of phenomena became of central focus. This presentation of Heidegger will be discussed in more detail later in the paper (Heidegger, 1999).

The actual union of the direct knowing of our mind of phenomena with the direct knowing of our awareness knowing the Being of phenomena reflects the full knowing of our ontic ontological nature.

There are many forms of phenomenology as expressed by the various masters of phenomenology. But the central formulation is the direct knowing of the essence of the phenomena being experienced and reflected upon within the medium of lived experience. Ultimately, the union of our two modes of knowing can bring forth our direct knowing of the essence of a singular phenomena and simultaneously the Being of the singular phenomena.

Our multidimensional mind shifts into different views of our phenomenological experience of phenomena. There is a phenomenological reduction and reflective gazing into the nature of the phenomena being experienced, viewed and understood within the translucidity of Transcendental Knowing. Transcendental Knowing is in 
essence the experience of Trans-lucidty. Trans-lucidity is the radiant illumination of the essence of phenomena.

\section{Intuitive Knowing and Intuitive Perceiving}

Transcendental Phenomenology focuses both on our direct intuitive knowing of the essence of a phenomena as well as Transcendental Phenomenology focuses on the nature of "Transcendental Knowing". Transcendental phenomenology focuses both on the act of "knowing" of the essence of a phenomena and transcendental phenomenology focuses on the nature of the phenomena that is being known. This is correlational knowing. Phenomenology describes this knowing as taking place within the noetic noema relationship. Noesis is the act of apprehending and noema is the apprehended. In both the act of apprehending and the noema is the apprehended in the light of the Trans-lucidity of Transcendental Knowing. Our mind has the luminous quality of Translucidity.

Our Transcendental knowing has vast and mysterious range. Mysteriously, transcendental knowing takes place within the transcendental dimension of our mind. Our transcendental knowing can go beyond our mind and our transcendental knowing can even go beyond the "knower" of mind. Husserl was not only interested in the phenomenology of the appearance of phenomena but Husserl had a disciplined emphasis on the phenomenology of the nature of Transcendental Knowing itself. Husserl intensely studied the subtle

experience of Transcendental Knowing. There are many forms of phenomenology. Within all these variations of phenomenology, the essential quality of phenomenology is the direct knowing or the direct intuition of the essence or what-ness of phenomena. 


\section{The Visible and the Invisible as Actual}

Some phenomenologist thought and some phenomenologist still think that transcendental knowing is non- existent, since transcendental knowing is not seemly constituted by physical form (Merleau-Ponty, 1968). Brentano an early philosophical source of phenomenological inspiration and a teacher at the University of Vienna of both Husserl and Freud challenged this concreate understanding. Psyche is invisible. The invisible psyche has no form but is still existent. Here Brentano is saying phenomena can be formless as well as forms. For Brentano Formless does not mean non existingness. Invisible phenomena and invisible experience can be both actual and real and the experience can be studied phenomenologically. For Brentano Being is formless existingness becoming forms. Some philosophical traditions equate existingness with concrete form. This equation itself is a form of concrete thinking. Transcendental Knowing can know formlessness and this formlessness is an actuality. The Transcendental Knowing is formless knowing. Formless Transcendental knowing knows both forms and formlessness (Brentano, 1960).

\section{Concrete Operational Thinking Limits Phenomenological}

\section{Knowledge}

The psychologist Jean Piaget describes brilliantly in his cognitive research on thinking the nature of concrete operational thinking. These concrete operational minds think really think that if the phenomena cannot be seen the phenomena does not exist. These concrete cognitive styles have rather primitive concrete understanding of causality. Cause and effect become concrete operational and linear like the apple falling on Newton's head. 
There is an unhappy cognitive limitation of concrete minded people. There is a density of thought and density of perception and density of affect and density of knowing that both reflects and sustain the concrete mind. Truth itself is thought to be totally concrete. Truth is a function of judgement. Concrete cognitive style persons love dogmatic belief and they also tend to love authoritarian leaders. The Authoritarian leader is the One who pretends Knowing absolutely. Concrete cognitive styles love the one who pretends to know absolutely. Hegel in his masterpiece "The Phenomenology of Spirit" elaborates how concrete minds often fall into the Master Slave relationship (Hegel, 2018).

\section{The Trans-lucidity of Transcendental Knowing and the Trans- lucidity of the Appearance of Phenomena}

Husserl's own study of transcendental states of mind or transcendental knowingness reflected Husserl's historical rootedness in Kantian transcendental thinking. In transcendental knowing awareness is a quality of mind that is intuitive and is the direct knowing of experience of the essential nature of experience. The essence of transcendental knowing is the trans-lucidity of phenomena as well as the trans-lucidity of Transcendental Knowing. The distinction in early phenomenology between mind and awareness did not exist. This lack of this important distinction can be a source of confusion in Transcendental phenomenology. This important later phenomenological distinction between mind and awareness helps us understand the wide range of human phenomena that phenomenological study reveals. 


\section{Phenomenological Dzogchen}

This ancient distinction was made within the Tibetan Dzogchen tradition in the 8th century CE in Tibet. This Dzogchen tradition went beyond the transcendental tradition of Indian Buddhism into a phenomenological philosophy of immanence. Kashmir Shavism is an Hindu Tantric tradition that makes the distinction between mind and awareness and is also a phenomenological experiential philosophy of immanence. What phenomenology names as direct knowing of Being, Dzogchen describes as Jnana or Gnosis (Lingpa, 2015).

\section{The Drama of Transcendence and Immanence in Phenomenological Experience and Understanding}

Husserl's phenomenology reflects the classical Transcendental Tradition of both western and eastern philosophy. Yet within the Transcendental Knowing there was for Husserl a subtle base of immanence. This base of immanence was within the transcendental experience. The Base of the transcendental experience was the light of Knowing, as the trans-lucidity of the light of knowing. Trans-lucidity illuminates experience and illuminates the nature of phenomena. The light of Trans-lucidity is the immanence of base within and of Transcendental Knowing.

Husserl equates his study of transcendentalknowing with the knowing within and of the mind. For early phenomenology direct knowing is simply an aspect of the mind. Direct knowing is both a kind of focusing of attention and is simultaneously direct luminous knowingness of intuition. This knowing was reflected as both ontic and ontological. Ontic means the actuality of mind and actuality of phenomena. Ontological means the actuality of Transcendental Being. Martin Heidegger in his 
writings made this important distinction between Ontic and Ontological. This distinction reflects the distinction between mind as the knowing of phenomena and awareness as the direct knowing of Being.

In the Path of Transcendental Phenomenology, the openness of our mind is thought to be the openness of our direct knowing into the unfolding path of the transcendental knowing of the essence of phenomena. There can be a further unfolding of our knowing opening into Transcendental knowing of Pure Transcendental Consciousness. This openness of transcendental knowing reflects the unfolding experience of transcendental radiance in its self - manifestation as the radiance of the Pure Presence of Consciousness. This realm of transcendental phenomenology is multidimensional and there is an fusion within the openness of the transcendental knowing and the translucidity of Pure Radiance of Consciousness. Husserl's work was a work of endless experimentation and discovery of the knowing of Transcendental Consciousness. Husserl's work is very similar to Freud's work with Freud's endless unfolding of discoveries within the psychoanalytic unconscious.

\section{The Brilliant Presence of Martin Heidegger and the Unfolding of Phenomenological Ontology}

In the Heideggerian understanding of phenomenology, awareness is both ontic and ontological. Awareness reflects the base of ontic knowing and awareness is simultaneously our ontological knowing of Being; Awareness is our opening to Being and our awareness is the radiance of Being. Heidegger called this openness to Being Da Sein. Human beings are ontic ontological Beings. The quality of this primordial awareness is spaceousness, radiance and light, openness, and vital energy of self 
manifestation. Heidegger understood that human awareness was directly knowing Being. He called this openness of our awareness to Being " $D a$ Sein".

\section{Phenomenological Knowing through Mind alone}

When a person only knows through their mind and only by their mind, there can be for the person an experiential absence of the embodiment of awareness. Moreover, there may be an experiential absence of the person's experiential sense of Being within the absence of the direct knowing of Being. There may be an experiential absence of their own felt sense of Being. In this absence of our embodied awareness knowing Being, the phenomenological mind is without the support of Being. The phenomenological mind is often not experientially in the field of Being. The phenomenological mind is often dissociated from the primordial field of awareness and the primordial field of Being.

When a person lives within the absence of awareness and lives within the absence of the experience of Being, there is a sense of absence of self. Phenomenologically, for some the sense self may be equated with the sense of the mind. Phenomenologically, the mind is not the self. The mind is not the true sense of the self and the mind is not the inner base of our ontological depth of our existential sense of self.

\section{The Sense of Self as Sense of Innermost Being}

Our sense of self is actually our experience of our embodied sense of Being. Our self is not our mind and our sense of self is not a thought or even a momentary affect or sensation or memory or imaginative image. Our Sense of Self is the Convergence of Our Sense of Embodied Being and Embodied Sense of Awareness. 
In the absence of the experiential awareness of embodied Being, Husserl's Transcendental phenomenology goes beyond the phenomena of our mind's observation, and Transcendental Knowing goes beyond our embodiment. Our Transcendental Knowing goes beyond the mundane world and our Transcendental Knowing goes beyond the phenomenological mind into vast subtle dimension of Transcendental Being. For some Transcendental Knowing is simultaneously beyond the mind and yet a deep potency within the mind. For some transcendental knowing is the innate base of the mind. Transcendental knowing empowers our mind and is the source of our minds knowing of the essence of phenomena.

\section{The Phenomenological Reduction}

In this way our unfolding of Transcendental Knowing can perceive, and directly intuit and know the essence of phenomena as well the elemental constitution of the phenomena of the world. From our Transcendental viewing we can perceive the essences of forms that constitute -manifestour embodiment and constitute -manifest- our mind and constitute and manifest our experience of the world. Husserl called this aspect of his phenomenological method the phenomenological reduction.

The more subtle the object, the more subtle the trans-lucidity of our observation of phenomena. The more subtle the transcendental realm, the more subtle the dimension of the essence of phenomena is perceived. The more subtle the phenomena, the more subtle the luminous knowing of transcendental knowingness is experienced. 


\section{The Process and Steps in Transcendental Phenomenology}

There are different dimensions of depth and subtleness of our Transcendental knowing. There are different steps in the unfolding process of Transcendental Knowing. The first movement in transcendental knowing is for a person through transcendental reflective detachment to go beyond cultural prejudice and to go beyond environmental prejudice and enter the viewing the natural world with less cultural prejudice. This step is entering the natural view of the phenomena.

The next step is through transcendental reflective detachment the transcendental phenomenologist goes beyond the density of embodiment, and then through reflective detachment within the mind enters and stabilize within witness consciousness. Within the transcendental witness consciousness and the gaze of witness consciousness the person experiences and knows directly the essence of the phenomena.

Then there is the final transcendental step and that is a leaping or dissolving into the realm of Pure Transcendental Consciousness without a knower. Knowingness without the knower is an unbound state of Transcendental Being. Pure Being as Pure Consciousness is Pure Transcendence. This same transcendental experience is found in many of the transcendental forms of eastern philosophy such as in Buddhism and in Vedantic Hinduism. This transcendental experience is also expressed and experienced in various forms of Christian Mysticism.

\section{The Phases of the Transcendental Phenomenological Reduction}

The Transcendental Phenomenological Reduction is Husserl's languaging and wording of the process of both entering into the experience of Transcendental knowing of the essence of phenomena and 
the Transcendental experience of going beyond phenomena into Pure Consciousness.

This accomplishment of the phenomenological reduction experience of Pure Transcendental Knowing has several phases. The use of the language of phenomenological reduction is an operational description of Husserl's phenomenological process.

\section{The Attempt to Suspend Cultural Prejudice}

In the first phase of the phenomenological reduction, there is the suspension of our cultural prejudice of our mind. Within this suspension of cultural prejudice, the phenomenologist can view and experience phenomena naturally as it manifest itself (Van Manen, 2014). This suspension is the suspending of particular cultural assumptions about a "phenomena". As Gadamer the hermeneutic phenomenologist points out the attempts at freeing ourselves from cultural and perceptual prejudice is a limited experience as there is aways implicit and intrinsic forms of cultural prejudice. At times the best we can do is to know them. Gadamer wrote the great text "On Truth and Method". As Jacque Lacan the master of symbolic psychoanalysis emphasized our cultural worlds of the symbolic realm which exist before we are born and we enter into this symbolic realm at birth and we become them.

\section{Epoche: The Opening Phase}

The unfolding opening phase of the transcendental phenomenological reduction is the Epoche which is the opening of our experience of our mind and our suspending the contextualiztion of our mind through detached reflection. Then by focusing on and seeing into phenomena through intuition and detached reflection a person is able to perceive 
directly and trans-lucidily phenomena from and within the transcendental gaze, thus knowing the subtle essence of the phenomena. The Epoche is a suspension of mental judgement and the opening of perceptual intuition.

This intuitive knowing is the essence of the transcendental phenomenological reduction. This direct knowing of essence is the direct intuition of the essence of phenomena. This is the trans-lucid illuminating experience of the nature of the phenomena.

\section{Transcendental Witness Consciousness}

This direct knowing arises by going beyond our ordinary psychological knowing of phenomena. The Transcendental Phenomenological knowing is an event that reflects entering the realm of the Transcendental Witness Consciousness. Transcendental Witness Consciousness is the objective and objectified onlooker. This Transcendental Perception of Witness Consciousness is the form of knowing that is the scientific ideal. The is the objectification of the non personal Transcendental onlooker viewing the essence of a phenomena.

\section{Beyond The Transcendental Witness}

There is still one further movement which can take place in the Transcendental Phenomenological Reduction. This is the transcendental movement of going beyond the experience of witness consciousness wherein the detached reflection of the witness becomes Pure Transcendental Knowingness without a Knower. This Transcendental Knowing is a transcendental event with the dissolving of the Personal Knower and what remains is Pure Consciousness. Some phenomenologist consider this Pure Consciousness as a form of absolute 
knowing. This is the knowing of Pure Consciousness. Eugene Fink who was the close associate of Husserl's suggested that this Transcendental realm is far beyond the mundane world, the ordinary life world.

\section{Pure Consciousness}

This ultimate experience of Transcendental Knowing is Pure Consciousness and Pure Consciousness is also Pure Being, Pure Transcendence. This is Pure Transcendental Consciousness, This Pure Transcendental Consciousness is complete in and of itself. As Husserl would so often say "what the wonder of all wonders. The wonder of all wonder's is pure consciousness and the doorway is our own subjectivity". This is the most complete form of the transcendental phenomenological reduction. This is the transcendental mystic experience

We see in this unfolding of the transcendental phenomenological reduction, the phenomenological knower of phenomena entering into the phenomenological reduction wherein the knower is in witness consciousness and enters into the intuitive knowing and direct perception of the essence of phenomena. This process may go further as the Transcendental phenomenologist unfolds themselves step by step into the Transcendental path of reflective detachment and transcendental knowing of Pure Being or Pure Consciousness. Thus phenomenological witness consciousness dissolves and disappears and what remains is Pure Knowingness as Pure Consciousness.

\section{Eastern Philosophical Transcendental Traditions}

This Phenomenological Transcendental process is very similar to the transcendental process of Indian Buddhism and transcendental forms of Vedantic Hinduism There is initially a transcendental experience of 
phenomena and transcendental view of the appearance of phenomena reflecting the transcendental view of the knower. The knower and the knowing of the known reflect the unfolding of subtle perception both with the knower and the luminous manifestion of the known. The knowing of the knower becomes one with the known. As the knowing and the known are in oneness and difference dissolves and the personal knower dissolves and what remains is Transcendental Knowing without the knower. Thus there is only transcendentalness remaining. Experientially there is only Pure Consciousness remaining (Bauer, 2019).

The formlessness of Being and the formlessness of the Being of phenomena can be experience within this realm of Transcendental Knowing of the Lucidity of Pure Consciousness. The Lucidity is the Purity of Transcendental Consciousness. The Lucidity is the Purity of Transcendental Being.

Transcendental knowing has the capacity to transcend both the objectification and personification of perception. This transcendence can be initially the detaching of our self from cultural prejudice. Our transcendence of cultural prejudice results for us being able to experience the natural world and the world of phenomena Our transcendence of our own cultural and psychological assumptions allows us to perceive directly the what-ness or the essence of our experience of the phenomena in the context of our transcendent translucent experience.

We perceive the essence of phenomena through witness consciousness. Then witness consciousness may be left behind, may dissolve and pure transcendental knowingness remains. What remains is the pure transcendence of phenomena, where there is only transcendental knowingness or pure consciousness. 
You can hear Gautama as the mythic "Buddha" giving his transcendental suggestion in the far background "Go beyond and Go beyond and Go beyond." Gate Gate Gate.

\section{The Unfolding Of the Phenomenological Ontology of Heidegger}

Phenomenological Ontology is also a form of Hermeneutical Phenomenology and a form of the Power of Direct Knowing of Being. For Martin Heidegger the transcendental understanding of phenomenology being a transcendental methodology is incomplete. The transcendental understanding limit's the power of our experience of embodied Being and our embodied knowing the Being of Phenomena and Being in and of itself. The transcendental process limits our experiencing the non duality of Being within duality of beings and experiencing the duality of beings within the non duality of Being. This difference is the essential difference between Traditions of Immanence and Transcendental Traditions.

Heidegger was an assistant to Husserl and over time challenged Husserl phenomenological Transcendental view. In time Heidegger brought forth the existential phenomenological understanding that human beings have and are the direct knowingness of awareness that he called Da Sein. Da Sein is the openness of awareness as our direct knowing of Being. Awareness directly knows Being. Da Sein is our human awareness knowing Being. Da Sein is not the knowing of mind, and not the mind's knowing of the forms of phenomena. Da Sein is awareness knowing Being. Da Sein is our radical human openness to Being (Binswanger, 1963). 


\section{Two Forms of Phenomenology: Ontic and Ontological}

Our mind can know the forms of phenomena and our awareness can know the Being of phenomena. Our mind is the ontic knowing of phenomena and our awareness is the ontological knowing of Being. We are ontic ontological Beings. For Heidegger ontological knowing has priority. The Da Sein knowing of Being is the knowing of Being within and through phenomena. This is the direct knowing of Being through our perceiving the phenomena as the manifestation of Pure Being. Phenomena is a form of Being (Marion, 2002).

\section{Heideggerian Phenomenology and the Direct Knowing of Being}

Heidegger goes beyond Husserl's understanding of the Transcendental knowing of mind and the Transcendentalization of mind. Heidegger urges the integration of the innate knowing of mind and the innate knowing of awareness. This is the integration of mind knowing phenomena and awareness knowing Being. This is the integration of mind directly knowing phenomena and awareness directly knowing Being. In Dzogchen language there is one knower with two forms of knowing. The knowing of mind knowing the essence of phenomena and the knowing of awareness knowing Being of phenomena.

\section{The Knower and The Known are in Oneness and in Difference}

The knowing of our mind knows the essence of phenomena and the knowing of our awareness directly knows Being. When our mind and our awareness enter union, we can know the Being of a phenomena and we can know the phenomena simultaneously. We can experience simultaneously phenomena and the Being of the phenomena and phenomena as Being itself. We can experience the phenomena of our own 
knowing as Being. We can experience our Being knowing Being as and within the phenomena. We can be within the oneness of Being within all phenomena. We can be and experience complete and total oneness within the phenomenological differences.

\section{Duality of Human beings within the Non Duality of Being}

We can experience within the duality of beings the non duality of Being and we can experience within the non duality of Being the duality of beings. This is the experience of embodied self liberation. This is the great shift in contemporary continental phenomenology and in our contemporary understanding about the nature of our knowing beings and experiencing their actuality of Being. The knower and the known are in the oneness of Being as Pure Being. The knower and the known as phenomenological beings are separate as differentiated phenomena.

This existential understanding has vast influence in contemporary theology, contemporary psychoanalysis and existential psychotherapy. This contemporary understanding has vast influence in contemporary mysticism. As the Dakini said to Dudjom Lingpa "You and I are indivisible". There is a you and there is an I and there is our indivisibleness (Lingpa, 2015).

\section{The Trans-lucidity of Seeing and Gazing: A Phenomenological Vision}

Heidegger has described his understanding of phenomenology as being a way of seeing and experiencing phenomena and seeing into phenomena and experiencing Being within all phenomena. Phenomenology is a way of directly experiencing Being within and through the Being of phenomena. In this perceiving and experiencing of Being, we become 
what we are experiencing. In experiencing Being we become what we are experiencing and knowing. Our Being is knowing Being. The knower and the known are in the oneness of Being. Through phenomena Being is perceived and directly experienced.

Within phenomena Being is perceived. We can describe this as a non conceptual and pre-reflective seeing or prereflective gazing or experiencing. Phenomenology is gazing into phenomena and through phenomena. Gazing is seeing or knowing or perceiving the Presence of Being within phenomenological beings and through phenomenological beings. We become what we are directly knowing. We become Being. We become what we are.

The knower and the known are in non dual oneness. This gazing reflects the union of the two ways of knowing within the one knower. This gazing opens the trans-lucidity of perception and the trans-lucidity of phenomena. This is not the form of objectified knowing of the subject and object view of our mind. Rather our Being knowing Being as Being in and through phenomenological forms of Being. As the Dakini said to Dudjom Lingpa "You and I are indivisible". Or as my teacher Erving Polster would so often say "two awareness's are better then one".

\section{The Heideggerian Phenomenological Reduction}

The focus of the Heideggerian Phenomenological Reduction is on the Opening of our human awareness to the direct Knowing of Being. The understanding of the phenomenological reduction as leading back to the transcendental life of consciousness in which phenomena and persons are constituted and manifested is not Heidegger's focus.

Heidegger's focus and understanding of the phenomenological reductions is: The unfolding of Phenomenological experience within the 
Apprehension of a being, no matter the Character of the apprehension of the being, is the direct knowing of the Being of this being.

In the union of the two ways of phenomenological knowing, there is the phenomenological knowing of a being and the direct intuition of the character of the being. What ever the character of the being, there is the direct phenomenological knowing of the Being of the being. Here the two distinct ways of knowing are two forms of phenomenology. The phenomenology of lucidity of mind knows the concrete manifestation of a being and the phenomenology of trans-lucidity of awareness knows the Being of the being. In this way the union of the two ways of phenomenological knowing accomplishes a completeness of our ontic ontological nature.

Husserl has described how in his early use of the word "constitution" he actually meant "manifestation."

In this context we experience the phenomenological shift as Da Sein takes the place of the objective Transcendental onlooker witness conscious beyond phenomena. There are two phenomenologies. The phenomenology of mind focuses on the concrete knowing of appearance from the of view of mind. The phenomenology of awareness is the phenomenological direct experiencing of the Being of the beings from within our ordinary life world. We see all phenomena as the field of Being in its self manifestation as singular phenomena, singular manifestation of Pure Being.

\section{Intertwined}

Contemporary Existential Phenomenological Methodology reflects the intertwined context of the knowing of Mind knowing phenomena and the Knowing of awareness directly knowing the Field of Being within and as 
singular beings. There is one knower with two ways of knowing simultaneously.

\section{The Phenomenological Reduction of Contemporary Existential Phenomenology: The Union of Two Ways of Knowing}

Applying the two distinct ways of knowing to our understanding of the existential phenomenological method of the phenomenological reduction sequence is most useful in understanding our onto -ontological context.

The first movement is the Existential Epoche. The Existential Epoche reflects the method of suspension of our mind's knowing of phenomena. Our mind is briefly paused or briefly suspended. This pause or this suspension briefly takes place, so that our awareness can become free from the contextualization of our mind. In this suspension of mind, our self awareness becomes self aware of awareness. In becoming self aware of awareness we become directly aware of Being.

This Existential Epoche brings forth the openness of awareness and consequently opens knowingness to and of the field of Being. This suspension of mind frees us from being located in our mind alone. This pause allows and supports our experience of the unbound openness of our awareness to directly and non conceptually know Being and experience Being. Our awareness can become self aware of its profound openness to and of luminous Being. In becoming self aware of our awareness we become aware of our Being since awareness is the direct knowingness of Being. Being knows Being through awareness. Awareness is the nature of our Being's knowingness.

Our Awareness directly and non conceptually knows Being and knows the Being of beings. Heidegger called this awareness knowing of Being Da Sein. Da Sein is the openness of awareness to direct knowing of Being. 
Da Sein is the trans-lucidity of awareness and trans-lucidity is the nature of the direct knowing of the Being of phenomena. Moreover, our awareness directly knows Being because awareness is Being's knowingness. Awareness is not a form of our minds knowingness but awareness reflects our Beings knowingness. In becoming self aware of our self awareness we become aware of our Being as knowingness. In becoming self aware of awareness we become directly aware of the translucidity of our awareness as the innate trans-lucidity of our own Being which is Pure Being itself. Amazing!

\section{Specific Steps of Contemporary Phenomenological Ontological}

\section{Process}

1. Epoche: The First Phenomenological Step is our Suspension of Mind or a Pause from being located in mind alone. By our mind we mean thinking, feeling, sensation, memory, imagination.

Our Mind is paused or suspended so that awareness can freely become self aware of awareness. Most often human beings are located in their mind alone. The are contained within the mind of thinking, feeling, sensation, memory, reasoning and imagination. So often the mind of people is dissociated from their awareness. Many people are separated from their knowing of the Being of their own being. In the lost of our base of Being, phenomena may seem beingless. Person's may seem to us to be beingless.

The most primary dissociation that human beings experience is the dissociation of their mind from the field of awareness which is ultimately the field of Being that they are. There is the separation of the ontic from the ontological dimension of experience. This is the source of much human suffering. 
In becoming aware of awareness we are open to the spaceousness of Being and the unbound openness of our own Being. Our innate awareness is most often aware of mind and in the active suspension of our mind, our awareness becomes freed to experience the power of our direct knowing of Being and the Being of beings.

\section{Integration of Our Mind Into Our Field of Awareness: Second Movement}

2. The next movement is the Integration of our mind and the functions of mind into the field of our awareness. We integrate our mind into the field of Being. We integrate seeing and hearing and thinking and feeling and sensation and imagination into the field of awareness which is the field of our Being. This integration of our mind within our field of awareness integrates our two ways of knowing. This is the ontic ontological experience of being human.

\section{Sense of Awareness, Sense of Self and Sense of Being}

3. This becoming aware of our own awareness is to become aware of our own Being and the Being of phenomena. Awareness is the knowingness of Being. So in becoming aware of our own awareness we become aware of our own Being. Our sense of awareness and our sense of Being is innately intimate. Our sense of self and our sense of awareness is innately intimate! When a person is beingless, a person is without sense of self. And when one is without awareness the person is without a sense of embodied self. Such a person will experience their mind as their self and they will lack the ongoing continuity of Being. Being located in mind alone, a person may live in Being- lessness. 
4. We also experience all phenomena as Being and as the manifestation of Being. No matter what the character of the phenomena we can experience the Purity of the Being of the phenomena. We can experience the indivisible connection between our own Being and the Being of the world. As the Dakini said to the Dzogchen Master Dudjom Lingpa "You and I are indivisible". The experience of Being of Pure Being is self liberating. The experience of the Pure Being of all phenomena is the experience of Equality Consciousness and Equal Vision. The experience of the Purity of Being of all human beings destroys innate cultural prejudice.

\section{The Wonderment of Phenomenological Ontological Experience}

5. There is a moment of wonderment. Awareness and the openness of awareness directly knowing Being brings forth wonder and Bliss. Wonder is the affective experience of Being and the experience of our Beingness of Being. The mind is paused and our awareness is freed and our subjectivity is free from being located and contained within mind alone. Our awareness which Heidegger called Da Sein knows Being. Awareness in union with our mind knows the Being of a Phenomena and the Phenomena of Being. Knowing phenomena with mind alone lacks the wonder of knowing the Being of phenomena. In mind alone the knowing of phenomena lacks the presence of Being. Eugene Fink the brilliant assistant to Husserl wrote about this wonderment of awareness and phenomenology. The masters of Tibetan Dzogchen also wrote about the wonderment of experiencing the field of awareness as the field of Being. The master's of Tibetan Dzogchen also wrote about the wonderment and Bliss of experiencing the field of awareness as the field of Being. 


\section{The Essential Shift}

The essential shift and movement is from knowing through our mind alone and then with this shift, our awareness knowing awareness opens our awareness to knowing Being. Awareness is the knowingness of Being. As awareness is open to self awareness knowing awareness, this awareness is an opening of our Being to Being itself and to the Being of all beings.

Mind is the knowing of phenomena and awareness is the knowing of Being. The openness of awareness is the openness of our direct knowing of Being. Awareness is the openness of Being knowing Being. Awareness is vast and multidimensional. When we integrate our mind into our field of awareness, we are integrating our mind into the experiential field of luminous Being.

\section{Openness of Awareness as the Openness of Wonderment and Bliss}

Within this opening, within this suspension of mind, there is our opening to the openness to Being. When we suspend our mind, the space is open for our experience of awareness. For us to experience awareness is to directly experience of Being. When there is the openness of our experience of awareness, there often arises the experience of Wonder and Bliss. When we enter into awareness which is our openess of our knowingness of Being, there will arises the experience of the Wonderment and Bliss. This sense of wonderment can continuously exist within our continuous experience of the ongoing continuity of Being. Wonder is intrinsic to our experience of the primordial awareness. Wonder of course is a form of Bliss. Bliss is ontological and not simply a psychological affect or psychological event of our mind. 
Phenomenologist describe the experience of the opening of the field of Being to our awareness as the Epoche. The Epoche is simply experiencing the openness of the field of Being. The spaceousness of awareness permeating our lived experience brings forth the trans-lucidity of phenomena. When a person enters this dimension of direct knowing of Being, the person will experience their innate intimate relationship with their Being as Being.

The Epoche is the experience of lived experience. We experience the phenomena of our lived experience within the context of awareness knowing the Being of the phenomena of our lived experience. By experiencing the lived experience of phenomena, we gaze into the lived experience of phenomena in the context of the manifestation of the Being of the phenomena and Being as the phenomena.

\section{Specific Steps of the Phenomenological Process within Contemporary Existential Phenomenology}

1. The first step of phenomenological experience and phenomenological knowing is the Epoche. The Epoche implies the experiencing of the openness of awareness. The further meaning of Epoche is the openness of our being to Being itself and to the Being of other beings. The Epoche is the natural openness of Being that we enter to. We become aware of our own awareness and in doing so, we experience the openness of our awareness to Being, to our own Being and the Being of others. The Epoche is the natural openness of Being and our entering into this natural openness of Being. So the first stage of phenomenology is to open our self to the field of Being. This is the opening of our Being to the field of Being. 


\section{Forms of Experience within the Existential Phenomenological}

\section{Process}

2. The Existential phenomenological reduction proper is the direct knowing of the lived experience of the Being of phenomena. When the mind is in union with the awareness field, the mind can know the essence of the phenomena and our awareness can directly know the Being of the phenomena. This is a simultaneous experience.

3. Both the knowing of the mind and the knowing of awareness is direct and intuitive knowing. There can be a simultaneous experience of the two phenomenologies which are our two ways of knowing.

4. There are different formulations of this direct knowing of lived experience of the manifestation of Being as a singular being. This praxis is the phenomenological illumination of our experience of the nature of a phenomena becoming visible and seen and directly experienced as Being. The experience of Being is the experience of luminous presence. The experience of Being brings forth wonderment and bliss.

\section{Other themes reflecting Our Existential Experience that are revealed within our Phenomenological Focus}

1. There is the Simultaneous Experience of the essence or whatness of Phenomena. Phenomenological Reduction is simply the language of experiencing the essence of the lived experience of the phenomena or the event of phenomena. When we are experiencing the nature of the phenomenological forms, the nature of the phenomena appears within the nature of the Being of the phenomena. This is a self illuminating experience of form and the Being of the forms. This is trans-lucid knowing of the nature of phenomena or the what-ness of phenomena or the character of the phenomena as well the Being of the phenomena. 
2. There is the Simultaneous Experience of the Beingness of Phenomena as well as the character of the phenomena. The ontological reduction is the experiential opening of our experiencing of the field of Being within a phenomenological focus. We now begin to experience the Being of the being or the Being of singular phenomena. We can experience the pure Being of beings no matter what the character of the being, no matter what the character of the phenomena.

3. We may also experience the Simultaneous Experience of the Givenness of the Phenomena. This experience is the radical experience of the self givenness of phenomena and our open knowingness of the self giving of Being to us as all phenomena.

4. We may also experience the Simultaneous Experience of the Inceptual process of Phenomenological Knowing. This is the direct experience of manifestation of our understanding as Aletheia. Aletheia is both a ontological and psychological event of the manifestation of Being. This is an Inceptual phase of the phenomenology of the unthought but known drama in the unfolding self manifestation of our understanding of our experience of illuminated phenomena. This is the process of self revelation of Being. This is the dimension of the self revelation of the Logos.

5. We may also have the Simultaneous Experience of Being and the Ordinary. This is often described as the Bliss of the Ordinary. There is a oneness between and the phenomenological sublime and the phenomenological Mundane. There is a continuity between the ontological and ontic spheres of experience. The ontological phenomenological reduction means leading phenomenological vision back from the apprehension of a being as Being. Whatever may be the character of that apprehension, the focus of understanding is the Being 
of this being. Self Liberation is living within Being. Self liberation is living within the Being of beings. Human beings are Being, Pure Being. To experience the luminosity of Being and Equality of Being is a way of profound self liberation.

\section{Conclusion}

I have reviewed the unfolding of the transcendental phenomenological reduction process and I have reviewed the unfolding of the ontological phenomenological reduction process as articulated by Heidegger and contemporary ontological phenomenology. I have also reviewed the phenomenological reduction in the light of contemporary Existential Phenomenology. Our discussion is elaborated in light of the two ways of knowing. The knowing of mind knowing phenomena, and the knowing of awareness knowing Being. The focus has been on the power of the intertwining of these ontic-ontological capacities. 


\section{References}

Bauer, R. (2019). The Absence of Self: An Existential Phenomenological View of the Anatman Experience. The Journal of Philosophical Investigations, Vol.13 (28).

Binswanger, L. (1963). Being in the World. New York: Basic Books.

Brentano, F. (1960). The distinction between mental and physical phe nomena. Trans. DB Terrell. In: R. Chisholm (ed.) Realism and the background of phenomenology. New York: The Free Press. IJHe.

Hegel, G. W. F. (2018). Hegel: The phenomenology of spirit. Oxford University Press.

Heidegger, M. (1999). Contributions to Philosophy. Bloomingdale, Indiana Press.

Husserl, E. (1964). The Paris Lectures. The Hague: Martinus Nijhoff.

Lingpa, Dudjom. (2015). The Vajra Essence. Wisdom Publications. Translated by Allan Wallace.

Marion, J. L. (2002). Being Given: Towards A Phe nomenology of Givenness. Sanford,Ca. Standford University Press.

Merleau-Ponty, M. (1968). The Visible and the Invisible. Evanston,Il: Northwestern University Press.

Van Manen, Max. (2014). Phenome nology of Practice. Left Coast Press, Walnut Creek, California. 